\title{
L1-Norm DVM ve Ki-Kare Tabanlı Öznitelik Seçme Algoritmaları ile Parkinson Hastalığının Konuşma Sinyalleri Üzerinden Saptanması
}

\author{
Fatih Demir \\ Elektrik ve Otomasyon Bölümü, Teknik Bilimler MYO, Fırat Üniversitesi, Elazığ, Türkiye \\ fatihdemir@firat.edu.tr (iD \\ Makale gönderme tarihi: 03.02.2021, Makale kabul tarihi: 10.03.2021
}

\begin{abstract}
$\ddot{O} z$
Parkinson hastalığı, genel nöro-dejeneratif bozukluklardan biridir. Konuşma / ses bozukluğu Parkinson hastalığının erken dönemdeki semptomlarından biri olarak kabul edilir. Ses sinyallerini işleme yöntemleri, Parkinson hastalığı ile ilgili ses bozukluğunu potansiyel olarak değerlendirebilir ve ölçebilir. Bu çalışmada, Parkinson hastalığını konuşma sinyallerinden teşhis etmek için etkili bir makine öğrenmesi tekniği önerilmiştir. Önerilen yöntemde, sağlıklı kişilerin ve Parkinson hastalarının konuşma sinyallerinden çıkarılan öznitelikleri içeren bir veri seti kullanılmıştır. L1-Norm Destek Vektör Makinesi ve Ki-Kare Tabanlı öznitelik seçme algoritmaları kullanılarak veri setinde bulunan ayırt ediciliği yüksek öznitelikler seçilmiştir. İki yöntemden elde edilen öznitelik setleri birleştirilerek sınıflandırma aşamasında kullanılmıştır. Sınıflandırma aşamasında Destek Vektör Makinesi, K-En Yakın Komşu ve Rasgele Alt Uzay K-En Yakın Komşu Toplulukları sınıflandırıcılarının tahmin sonuçlarının kullanıldığı Çoğunluk Oylaması yöntemi ile önerilen yöntemin başarımı artırılmıştır. Önerilen yöntem \%95.11 doğruluk ile aynı veri setini kullanan geçmiş çalışmalara göre daha iyi bir performans sağlamıştır. Önerilen yöntem ile Parkinson hastalığı otomatik olarak teşhis edileceğinden bu uygulama hekimlere karar verme süresinde yardımcı bir araç olarak kullanılabilir.
\end{abstract}

Anahtar Kelimeler: Konuşma sinyalleri, öznitelik seçme, Parkinson hastalığı, sınıflandırma

\section{Detection of Parkinson's Disease using Speech Signals with L1-Norm SVM and Chi-Square Based Feature Selection Algorithms}

\begin{abstract}
Parkinson's disease is one of the common neurodegenerative disorders. Speech / voice impairment is considered as one of the early symptoms of Parkinson's disease. Sound signal processing methods can potentially assess and measure Parkinson's disease-related sound impairment. In this study, an effective machine learning technique has been proposed to diagnose Parkinson's disease from speech signals. In the proposed method, a data set containing features extracted from speech signals of healthy people and Parkinson's patients was used. Highly distinctive features in the data set were selected using L1-Norm Support Vector Machine and Chi-Square Based feature selection algorithms. The feature sets obtained from the two methods were combined and used in the classification stage. In the classification stage, the achievement of proposed method was increased with majority voting method, which used the prediction results of Support Vector Machine, K-Nearest Neighbor and Random Subspace K-Nearest Neighbor Ensembles classifiers. The proposed method with $95.11 \%$ accuracy outperformed previous studies using the same dataset. Since Parkinson's disease will be diagnosed automatically with the proposed method, this application can be used as a helpful tool for physicians in their decisionmaking process.
\end{abstract}

Keywords: Classification, feature selection, Parkinson's disease, speech signal

\section{GİRIŞ̧}

Parkinson hastalığı $(\mathrm{PH})$, beyin hücrelerinin bozulmasına veya ölümüne yol açan ilerleyici, kalıcı bir nörolojik hastalıktır. Hafiza sorunları, depresyon, yavaşlık, sertlik ve titreme gibi hareket bozukluklarını içeren çeşitli semptomları vardır. Ayrıca PH hastalığının son evrelerinde yürüme ve denge problemleri gözlenir (Calabresi, Picconi, Parnetti, ve Di Filippo, 2006). Genel olarak beş ana $\mathrm{PH}$ aşaması vardır. En erken evrede (1. aşama), $\mathrm{PH}$ hastalarında vücudun bir tarafinda, elde veya bacakta sertlik ve titreme gibi hafif semptomlar gözlenir (Jankovic, 2008). 2. aşamada, PH hastalarında 
konuşma anormallikleri, yüz ifadesi kaybı, gövdenin kas sertliği ve eğik duruş problemleri ortaya çıkar (Friedlander, Mahler, Norman, ve Ettinger, 2009). Orta aşamada (3. aşama), hastada yavaş hareket etme, denge kaybı ve düşme gibi sıkıntılar baş gösterir. Son iki şiddetli aşamada (4. ve 5. aşama), hastalar yardım olmadan ayakta durmaz ve yürüyemezler. Dahası, hastanın fiziksel ve zihinsel canlılığ 1 azalır (Bloem, Grimbergen, Cramer, Willemsen, ve Zwinderman, 2001). Bununla birlikte, tüm hastalar PH ilerlemesinin bu beş aşamasını birden yaşamayabilir. Ayrıca, bu beş aşamanın şiddeti ve süresi hastadan hastaya değişir. $\mathrm{Bu}$ durum, araştırmacıları böyle değișken bir araştırma alanını keşfetmeye yöneltirken, PH saptama modelleri geliştirmedeki zorlukları da beraberinde getirmektedir (Ashour, ElAttar, Dey, Abd El-Naby, ve Abd El-Kader, 2018).

PH izleme ve tele-tıp sistemleri için, hastalığın erken aşamada tespiti ve teşhisi önemli hale gelmektedir. PH hastalığının erken evrelerinde, monoton ses, yumuşak ses, gevrek konuşma ve yüksek sesle konuşmaya başladıktan sonra ses seviyesinin azalması gibi konuşma anormallikleri gözlenir (Ramig, Fox, ve Sapir, 2004; Trail ve ark., 2005). PH hastalarında sesin özelliklerindeki bu değişiklikler, öznitelik çıkarma prosedürlerini ve siniflandırma tekniklerini kullanmaya dayalı olarak PH'ın erken tespiti için kilometre taşı olarak kabul edilmektedir. Sonuç olarak, son çalışmalar PH ile konuşma kaybı ve zayıflığı arasında kuvvetli bir ilişki olduğunu göstermiştir. Bu iddia, akustik artikülasyon, aruz ve fonasyon analizi yoluyla Goberman (2005) tarafından doğrulanmıştır. Sonuçlar, on altı konuşma özelliğinden yedi akustik ölçümün, yüz ifadesi, yürüyüş, duruş dengesi, dinlenme halindeki titreme ve ayaktaki titreme gibi hareket ölçümleriyle önemli ölçüde ilişkili olduğunu göstermiştir. OrozcoArroyave ve ark. (2016), Almanca, Çekçe ve İspanyolca gibi farklı dillerin kaydedilmiş konuşmaları üzerine başka bir çalışma yapmıştır. Başlangıçta, sessiz ve sesli çerçeveleri ayırmak için konuşma sinyallerine bir bölümleme işlemi uygulanmıştır. Daha sonra, sessiz seslerin enerjisi Bark ölçeği ve 12 Mel-frekans Cepstral Katsayıları (MFCK) kullanılarak modellenmiştir. Bu yaklaşım ile PH hastaları konuşulan dile göre \%85 ile \%99 arasında doğrulukla saptanmıştır. Tsanas ve ark. (2012), hem sağliklı bireylerin hem de PH hastalarının konuşma sinyallerindeki hışırtı ve titreme özniteliklerinin yanı sıra çok sayıda disfoni özniteliği (132 disfoni ölçümü) çıkarmıştır. Sınıflandırma performansını artırmak için, minimum Fazlalık Maksimum Uygunluk (mFMU), Yerel Öğrenme Tabanlı Öznitelik Seçimi (YÖTÖS), En Az Mutlak Daralma (EAMD) gibi farklı öznitelik seçimi yöntemleri kullanılmıştır. Son olarak, sağlıklı bireyleri PH hastalarından ayırt etmek için Destek Vektör Makineleri (DVM) ve Rastgele Değişken (RD) sınıflandırıcıları kullanılmıştır.

$\mathrm{Bu}$ çalışmada, $\mathrm{PH}$ hastalığının otomatik tespiti için konuşma sinyallerinden çıkartılan konuşma tabanlı bir öznitelik veri seti kullanılmıştır. Bu özniteliklerden yüksek seviyeli olanları çıkarmak için L1-Norm DVM ve Ki-Kare algoritmaları kullanılmıştır. Sınıflandırma başarımını artırmak için bu iki algoritmadan elde edilen öznitelik seti birleştirilmiştir. Sınıflandırma aşamasında, DVM, KEYK ve RAUKT sınıflandırıcıları kullanılmıștır. Sınıflandırma performansını artırmak için ÇO yöntemi kullanılmıştır.

Makalenin kalan kısmında materyal ve yönteme ikinci bölümde, deneysel çalışmalar ve sonuçlara üçüncü bölümde ve tartışmaya dördüncü bölümde değinilmiştir.

\section{MATERYAL VE METOT}

$\mathrm{Bu}$ çalışmada, sağlıklı ve $\mathrm{PH}$ vakalarının ses özniteliklerden otomatik PH tespiti yapılmıştır. İlk aşama olarak kullanılan konuşma tabanlı öznitelik veri setindeki öznitelikler içinden yüksek temsil gücüne sahip olanlar L1-Norm DVM ve Ki-Kare algoritmaları ile seçilmiştir. L1-Norm DVM algoritmasında seçilen özniteliklerin sayısı DVM algoritmasında kullanılan cezalandırma parametresi (C) ile belirlenmiştir. Ki-Kare algoritmasında ise seçilecek olan öznitelik sayısı direkt parametre değeri olarak girilmiştir. $\mathrm{Bu}$ algoritmaların performansları DVM, K-EYK ve RAUKT siniflandirıcilarında test edilmiştir. En iyi performans her iki algoritmadan elde edilen öznitelik setinin birleştirilmesi ile elde edilmiştir. Sınıflandırma aşamasında, DVM, K-EYK ve RAUKT sınıflandırıcılarının tahmin sonuçları kullanılarak nihai tahmin sonucu Çoğunluk Oylaması (ÇO) yöntemiyle belirlenmiştir. ÇO yönteminde temel olarak, kullanılan her siniflandirıcinın aynı örnekteki tahmin sonuçlarını bakıldıktan sonra hangisi çoğunluktaysa o sonuç kullanılmıştır. Önerilen yöntemin grafiksel özeti Şekil 1'de verilmiştir. 


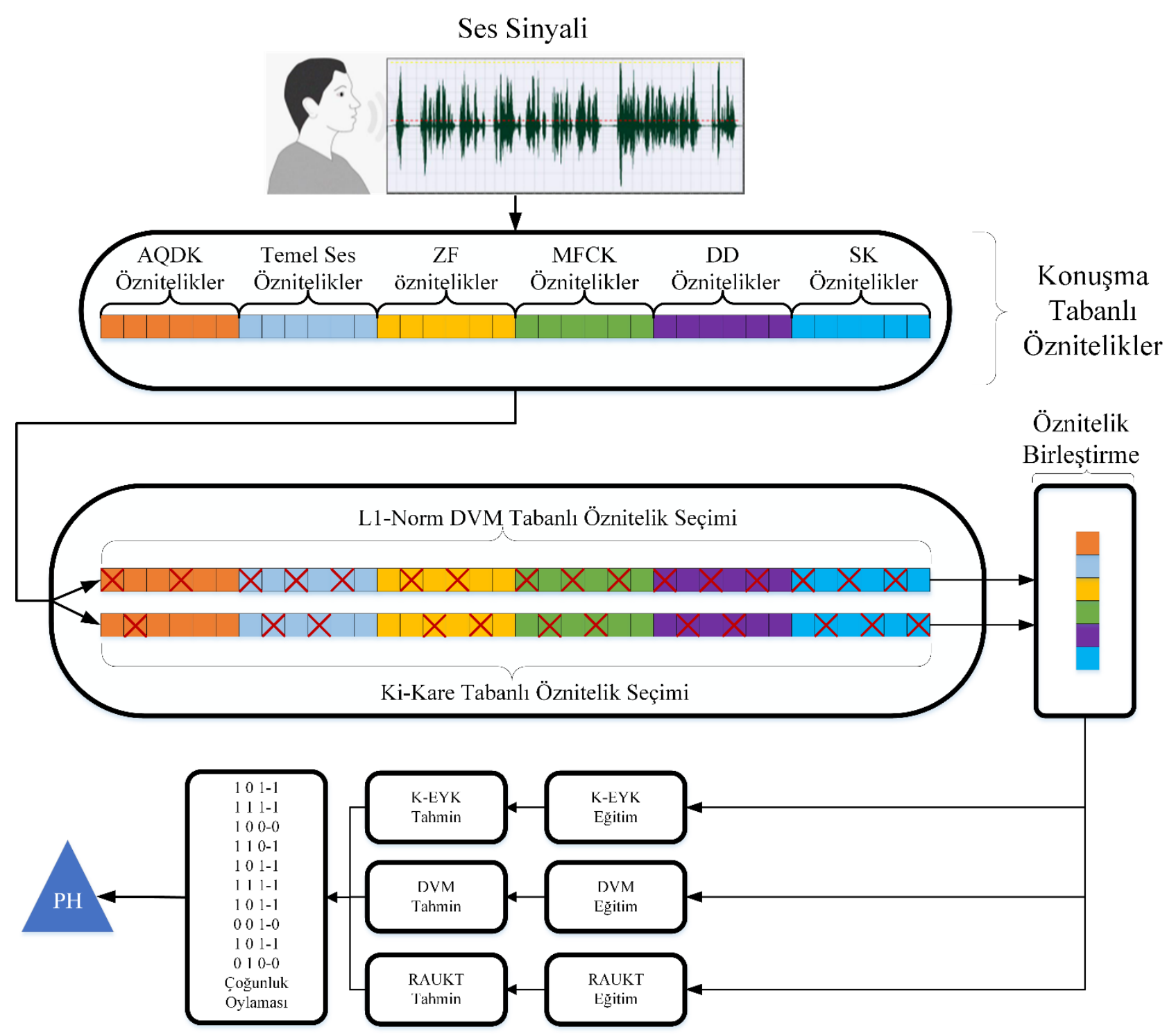

Şekil 1. Önerilen yöntemin grafiksel gösterimi

\section{Ki-Kare Tabanlı Öznitelik Seçimi}

Ki-Kare algoritmasinda (Kira ve Rendell, 1992) bir $t_{i}$ öznitelik seti, bir $C_{j}$ sinıfı ile korelasyonuna göre seçilir ve $t_{i}$ öznitelik setinin $C_{j}$ sınıfına göre ayırt etme yeteneği şu şekilde hesaplanır:

$x^{2}\left(t_{i}, C_{j}\right)=\frac{\mathrm{N} \times\left(\mathrm{a}_{\mathrm{ij}} \mathrm{d}_{\mathrm{ij}}-\mathrm{b}_{\mathrm{ij}} \mathrm{c}_{\mathrm{ij}}\right)^{2}}{\left(\mathrm{a}_{\mathrm{ij}}+\mathrm{b}_{\mathrm{ij}}\right) \times\left(\mathrm{a}_{\mathrm{ij}}+\mathrm{c}_{\mathrm{ij}}\right) \times\left(\mathrm{b}_{\mathrm{ij}}+\mathrm{c}_{\mathrm{ij}}\right) \times\left(\mathrm{c}_{\mathrm{ij}}+\mathrm{d}_{\mathrm{ij}}\right)}$

Burada $N$, toplam örnek sayısıdır. $a_{i j}, t_{i}$ özniteliğini içeren $C_{j}$ kategorisindeki örnek sayısıdır ve $b_{i j}, C_{j}$ kategorisindeki $t_{i}$ özniteliğini içermeyen örneklerin sayısıdır. $c_{i j}, t_{i}$ özniteliğini içeren fakat $C_{j}$ kategorisine ait olmayan örneklerin sayısıdır. $d_{i j}$, $C_{j}$ kategorisine ait olmayan ve $t_{i}$ özniteliğini içermeyen örneklerin sayısıdır.

\section{L1-Norm DVM Tabanlı Öznitelik Seçimi}

L1-Norm tabanlı öznitelik seçiminde öznitelik sayısını maliyet parametresi $(C)$ belirler. $\mathrm{N}$ örneğe sahip bir veri seti $(S)$ Eşitlik 2'deki gibi ifade edilmiştir.

$S=\left\{\left(\mathrm{x}_{\mathrm{i}}, \mathrm{y}_{\mathrm{i}}\right) \mid \mathrm{x}_{\mathrm{i}} \in \mathrm{R}^{\mathrm{n}}, \mathrm{y}_{\mathrm{i}} \in\{-1,1\}\right\}_{\mathrm{i}=1}^{\mathrm{k}}$ 
Burada $\mathrm{x}_{\mathrm{i}}, \mathrm{n}$ adet özniteliğe ve bir sinıf etiketine $\left(y_{i}\right)$ sahip olan i. örnektir.

İki sınıflı sınıflandırma probleminde (Eşitlik 3) DVM, kenar payını maksimum yapan ayırıcı hiper düzlemi öğrenir (Haq ve ark., 2019).

$\mathrm{y}_{\mathrm{i}}\left(\mathrm{wx}_{\mathrm{i}}-\mathrm{b}\right) \geq 1, \mathrm{i}=1, \ldots, \mathrm{k}$

Burada, w ağırlık vektörü ve $b$ ise bias vektörüdür. Eşitlik 3 'teki problemi baz alarak Eşitlik 4'te belirlenen optimizasyon probleminin çözümlenmesi gerekir.

$\min \frac{1}{2}\|\mathrm{w}\|^{2}$

Eşitlik 3'te belirlenen eşitsizlik, kenar payının yakınındaki mesafeden kaynaklanan sinıflandırma hatalarını düzeltmek için Eşitlik 5'teki gibi yeniden düzenlenebilir.

$\mathrm{y}_{\mathrm{i}}\left(\mathrm{wx}_{\mathrm{i}}-\mathrm{b}\right) \geq 1-\delta, \delta \mathrm{i} \geq 0, \mathrm{i}=1, \ldots, \mathrm{k}$

Bradley ve Mangasarian (1998)ise, ortaya çıkan seyrek çözümlerin bir sonucu olarak L1-Norm DVM tabanlı öznitelik seçimi için Eşitlik 5'i kısıt kabul ederek Eşitlik 6'yı kullanmıştır.

$\min \|\mathrm{w}\|^{1}+\mathrm{C} \sum_{\mathrm{i}=1}^{\mathrm{k}} \max \left(0,1-\mathrm{y}_{\mathrm{i}}\left(\alpha^{\mathrm{T}} \mathrm{x}_{\mathrm{i}}+\mathrm{b}\right)\right)^{2}$

Burada $\alpha$, Lagrange (Guo, Guo, Chen, ve Jiang, 2017) optimizasyon çarpanlarından elde edilen ağırlık vektörüdür. Ayrıca, Eşitlik 6'da kullanılan C parametresinin değeri öznitelik boyutunu belirlemektedir.

\section{DVM Sinıflandırıcısı}

Sinıflandırma sürecinde DVM algoritmas1, çeşitli makine öğrenmesi problemlerinde genel olarak iyi performans sağladığ için literatürde sıklıkla tercih edilmektedir (Cortes ve Vapnik, 1995; Turhan, Sengür, Karabatak, Guo, ve Smarandache, 2018). DVM algoritmasında ikili bir sinıflandırma problemi için örnekler bir hiper düzlem $\left(\mathrm{w}^{\mathrm{T}} \mathrm{x}_{\mathrm{i}}+\mathrm{b}=0\right)$ ile ayrılır. En iyi ayrımın yapılması için $w$ ağırlık vektörünün optimize edilmesi gerekmektedir. Lagrange optimizasyon algoritması kullanılarak elde edilen $w$ ağırlık değerlerinin Eşitlik 7'yi sağlaması gerekmektedir. $w=\sum_{\mathrm{i}}^{\mathrm{n}} \alpha_{\mathrm{i}} \mathrm{y}_{\mathrm{i}} \mathrm{x}_{\mathrm{i}}$

Burada, $n$ destek vektörlerinin sayısı, $y_{i}$ sinıf etiketlerini, $x_{i}$ giriş veri setini ve $\alpha_{i}$ Lagrange çarpanlarını temsil etmektedir. Doğrusal ve doğrusal olmayan durum için DVM algoritmasının karar verme fonksiyonu sırasıyla Eşitlik 8 ve Eşitlik 9'da verilmiştir.

$f(x)=\operatorname{sgn}\left(\sum_{\mathrm{i}}^{\mathrm{n}} \alpha_{\mathrm{i}} \mathrm{y}_{\mathrm{i}} \mathrm{x}_{\mathrm{i}}^{\mathrm{T}} \mathrm{x}+\mathrm{b}\right)$

$f(x)=\operatorname{sgn}\left(\sum_{\mathrm{i}}^{\mathrm{n}} \alpha_{\mathrm{i}} \mathrm{y}_{\mathrm{i}} \mathrm{K}\left(\mathrm{x}_{\mathrm{i}}, \mathrm{x}\right)+\mathrm{b}\right)$

Eşitlik 9'daki K, çekirdek fonksiyonunu temsil etmektedir. Lineer olmayan durumlarda çekirdek fonksiyonu sayesinde örnekler başka uzaya taşınıp doğrusal hale getirilmektedir.

\section{K-EYK Sinıflandırıcisı}

K-En Yakın Komşuluk (K-EYK) algoritması, gözetimli öğrenme kategorisinde olup hem sınıflandırma hem de bağlanım problemleri için kullanılmakla beraber genelde pratiğe dayalı uygulamalarda sinıflandırma problemlerinin çözümü için de tercih edilmektedir (Sengür ve Turhan, 2018). Cover ve Hart (1967) tarafindan öne sürülen K-EYK algoritmasında önceden belirlenmiş etiketleri olan bir veri seti ile değerlendirme yapılmıştır. K-EYK algoritmasında, sınıflandırılacak olan yeni veriler etiketlenmiş veri seti üzerinden sınıflandırılmaktadır. Yeni verinin hangi sınıfa ait olduğunu belirlemek için etiketli veri setindeki verilerle uzaklık durumuna bakılmaktadır. Bu uzaklıklar Eşitlik 10 ile Eşitlik 12 arasında verilen Öklid, Minkowski ve Manhattan gibi uzaklık denklemleri ile hesaplanmaktadır.

Öklid $=\sqrt{\sum_{i=1}^{n}\left(x_{i}-y_{i}\right)^{2}}$

Manhattan $=\sqrt{\sum_{i=1}^{n}\left|x_{i}-y_{i}\right|}$

Minkowski $=\left(\sqrt{\sum_{i=1}^{n}\left|x_{i}-y_{i}\right|^{k}}\right)^{1 / k}$

Minkowski uzaklık denkleminde $k, 1$ seçilirse Manhattan $k$, 2 seçilirse Öklid uzaklık denklemi elde edilmektedir. 


\section{RAUKT ile Sinıflandırma}

RAUKT

algoritmas1,

sınıflandırıcılarının sınıflandırma doğruluğunu artırmak için rastgele alt uzay topluluklarının kullanıldığı bir yöntemdir. Bu yöntemde, her alt uzaydaki sınıflandırıcı oluşturulurken öğrenme modeline bir dizi bileşenini rastgele seçen bir işlem uygulanmaktadır (Adem, 2020). Her sınıflandırıcıdaki eğitim veri seti rastgele alt uzaylara bölünmekte ve bu eğitim seti üzerinde test örnekleri kullanılarak Öklid ve Chebyshev gibi mesafe hesaplamaları yapılmaktadır. Her siniflandirıcida en yakın komşu sayısına $(K)$ göre en uygun alt uzay sınıf üyeliği belirlendikten sonra, tüm alt uzay sinıflandırıcılarından gelen tahmin sonuçlarının ortalaması alınmaktadır (Ho, 1998). En son olarak ortalaması alınan tahmin sonuçları en uygun üyeliğe sahip sinıfa atanmaktadir. Temel RAUKT algoritmasında aşağıdaki adımlar uygulanır:

Adım 1: $\mathrm{M}$ boyutlu bir eğitim veri etinden $\mathrm{N}$ boyutlu bir alt uzay veri setini $\mathrm{L} \mathrm{kez}$ rastgele seçin.

Adim 2: Bir adet K-EYK siniflandiricisin yalnızca seçilen tahmin unsurlarını kullanarak eğitin.

Adım 3: L adet K-EYK sinıflandirıcisını olana kadar 1. ve 2. adımları kullanarak eğitin.

Adım 4: L adet K-EYK sinıflandıricisının tahmin değerlerinin ortalamasını alın.

Adım 5: Test veri kümesini en uygun sinıfa atanacak şekilde sınıflandırın.

\section{Veri Seti}

Kullanılan veri setini oluşturmak için $188 \mathrm{PH}$ vakası ve 64 sağlıklı birey kullanılmıştır. Her denekten üçer kez ses kaydı alınarak veri setinin örnek sayısı 756'ya çıkarılmıştır. Her örnek için genel olarak 7 ayrı konuşma tabanlı öznitelik algoritması kullanılarak veri setindeki her bir ses kaydının boyutu öznitelik boyutuna (753) indirgenmiştir (Sakar ve ark., 2019). Konuşma tabanlı bu öznitelikler MFCK, Temel Ses, Zaman-Frekans (ZF), Dalgacik Dönüşümü (DD), Ses Katlamalı (SK) ve Ayarlanabilir Q Faktör Dalgacık Katsayısı (AQDK) algoritmaları ile elde edilmiştir. $\mathrm{Bu}$ algoritmalardan kaç adet öznitelik çıkarıldığı Tablo'1 de verilmiştir.

\section{Performans Ölçüm Metrikleri}

Önerilen yaklaşım için karmaşıklık matrisindeki doğru pozitif (DP), doğru negatif(DN), yanlış pozitif (YP), yanlış negatif (YN) sayıları kullanılarak performans ölçüm metrikleri hesaplanmıştır.
Performans ölçütleri doğruluk, duyarlılık, özgüllük, kesinlik ve F-skor değeri kullanılarak oluşturulmuştur. Performans ölçüm metrikleri aşağıdaki eşitlikler ile hesaplanmıştır.

Doğruluk $=\frac{\mathrm{DP}+\mathrm{DN}}{\mathrm{DP}+\mathrm{DN}+\mathrm{YP}+\mathrm{YN}}$

Duyarlılık $=\frac{\mathrm{DP}}{\mathrm{DP}+\mathrm{YN}}$

Özgüllük $=\frac{\mathrm{DN}}{\mathrm{DN}+\mathrm{YP}}$

Kesinlik $=\frac{\mathrm{DP}}{\mathrm{DP}+\mathrm{YP}}$

$F-s k o r=2 \times \frac{K s \times D u}{K s+D u}$

\section{DENEYSEL ÇALIŞMALAR}

$\mathrm{Bu}$ çalışmadaki deneysel sonuçları elde etmek için Python ve Matlab ortamı kullanılmıştır. L1Norm DVM ve Ki-Kare algoritmalarıyla öznitelik seçimi Pyhton'da, sınıflandırma işlemi ise Matlab'ta gerçekleştirilmiştir. L1 -Norm DVM algoritmasında $C$ parametresi 0.4 seçilmiştir ve bu algoritma ile 40 adet ayırt edici öznitelik çıkartılmıştır. Ki-Kare algoritmasında ise öznitelik sayısı 50 ile 450 arasında 50'nin katları şeklinde denenmiștir. Kullanılan tüm sınıflandırıcılar için en iyi sonuç doğruluk metriğine göre 250 öznitelik ile elde edilmiştir. Her iki öznitelik algoritmasinın performans1 ayr1 olarak değerlendirilmiştir. Fakat özniteliklerin birleştirilmesiyle her sınıflandırıcının doğruluk performans1 \%2-5 arasında artmıştır. Toplamda kullanılan 290 adet öznitelik kullanarak veri setinde bulunan örneklerin konumu sınıf ayrımı yapılarak Şekil 2'de verilmiştir. Şekil 2'den görüleceği üzere bu örneklerin bazıları doğrusal olarak ayrılabilirken bazıları ayrılamamaktadır. Bunun için doğrusal olmayan sınıflandırıcılar kullanılmıștır.

Sınıflandırma aşamasında, DVM, K-EYK ve RAUKT sınıflandırıcıları kullanılmıştır. DVM sınıflandırıcısı için en iyi sonuç polinominal 3 . dereceden çekirdek fonksiyonuyla elde edilmiştir. Ayrıca hiperparametre olan çekirdek boyutu ve kutu kısıtlaması sırasıyla 'otomatik' ve ' 1 ' seçilmiştir. KEYK sinıflandırıcısında en iyi performans için uzaklık denklemi, en yakın komşu sayısı sırasıyla 'Öklid' ve ' 1 ' seçilmiştir. RAUKT sınıflandırıcısında ise öğrenme periyodunun sayıs1 ' 30 ' seçilmiştir. 


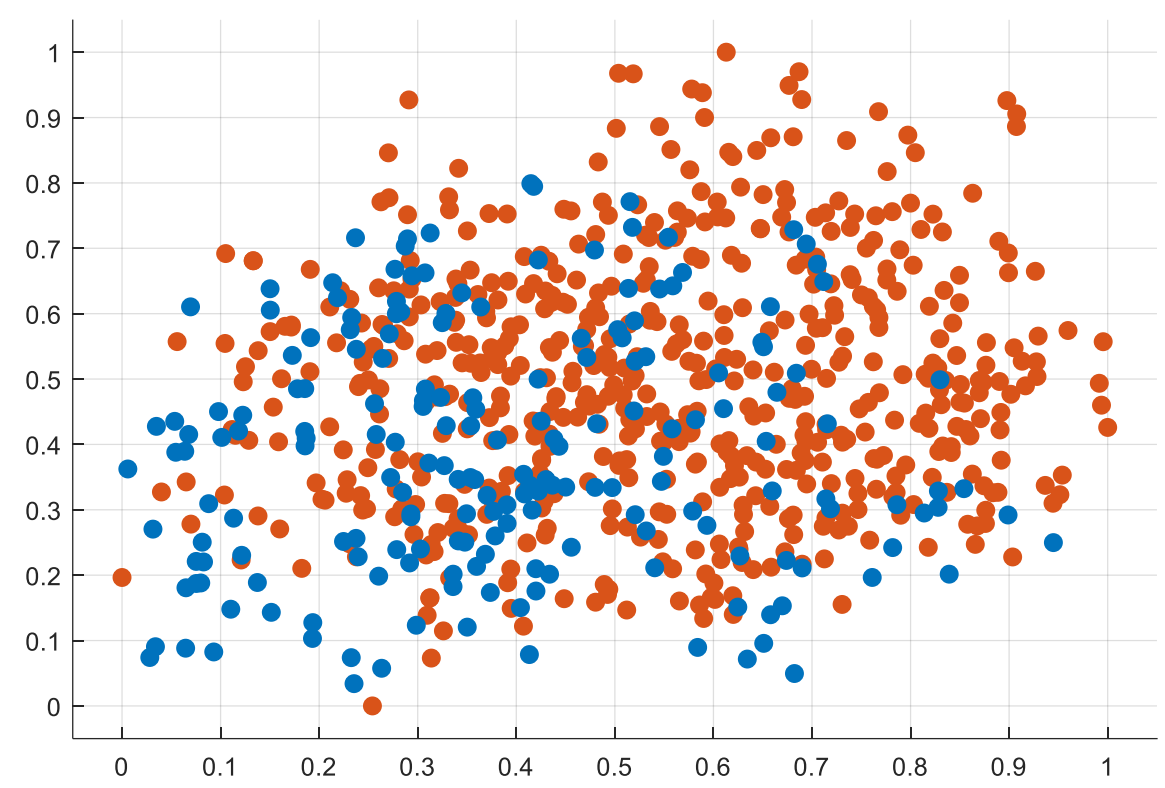

Şekil 2. Çıkartılan öznitelikler ile örneklerin saçılım grafiği

Tablo 1. Algoritmalara göre öznitelik sayıları

\begin{tabular}{c|c}
\hline Konuşma Tabanlı Öznitelik Algoritmaları & Öznitelik Sayısı \\
\hline Temel Ses & 21 \\
\hline ZF & 11 \\
\hline MFCK & 84 \\
\hline DD & 182 \\
\hline SK & 16 \\
\hline AQDK & 439 \\
\hline
\end{tabular}

Şekil 3'te DVM, K-EYK, RAUKT ve ÇO algoritmaları kullanılarak elde edilen karmaşıklık matrisi sonuçları 10-kat çapraz doğrulama yapıldıktan sonra verilmiştir. Şekil 3'e göre tek sınıflandırıcı kullanıldığında en kötü doğruluk sonucu DVM sınıflandırıcısıyla elde edilirken en iyi sonuca RAUKT sınıflandırıcısıyla ulaşılmıştır. Üç sınıflandırıcının tahmin sonuçlarını kullanan ÇO yöntemiyle en iyi doğruluk \%95.11 olarak sağlanmıştır.

Tablo 2'de önerilen metotta kullanilan sınıflandırıcıların ve ÇO ile sınıflandırma işleminin duyarlılık, özgüllük, kesinlik ve F-skor sonuçları verilmiştir. Duyarlılık metriği için en kötü sonuç DVM sınıflandırıcısının Parkinson sınıfı için alınmıştır. Özgüllük metriği için en kötü sonuç yine DVM sınıflandırıcısının Normal sınıfı için alınmıştır. Kesinlik metriği için en kötü sonuç K-EYK sınıflandırıcısının Parkinson sınıfı için alınmıştır. En iyi sonuçlar ise her iki sınıf için ÇO metodu kullanılarak alınmıştır.

Tablo 3'te, önerilen yöntemle aynı veri setini kullanan literatürdeki diğer yöntemlerin performans metrikleri verilmiştir. 


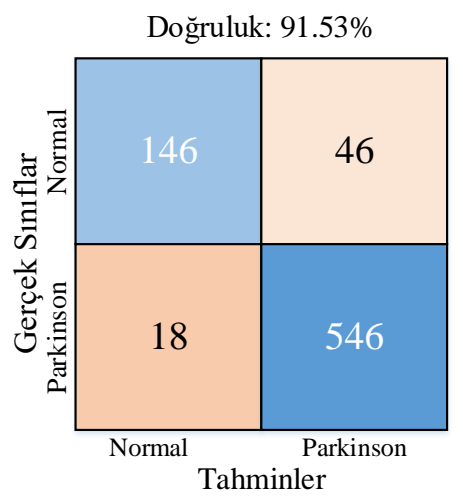

(a)

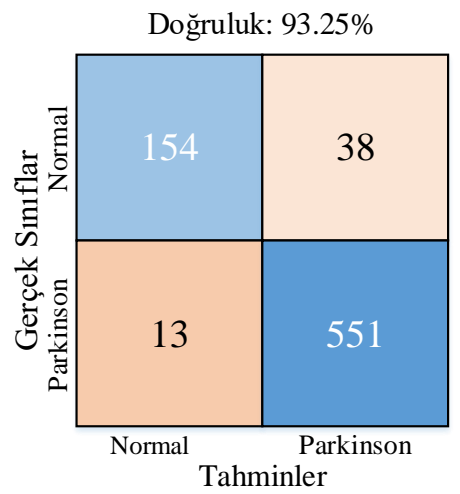

(c)

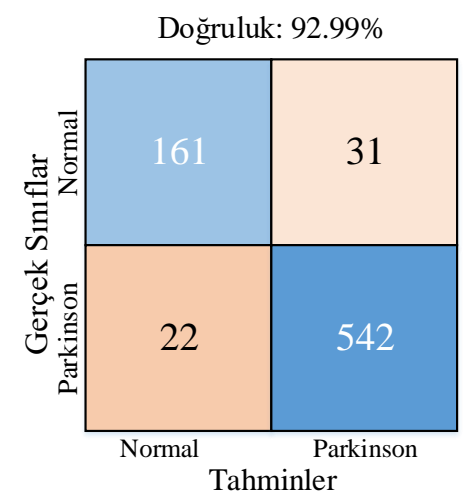

(b)

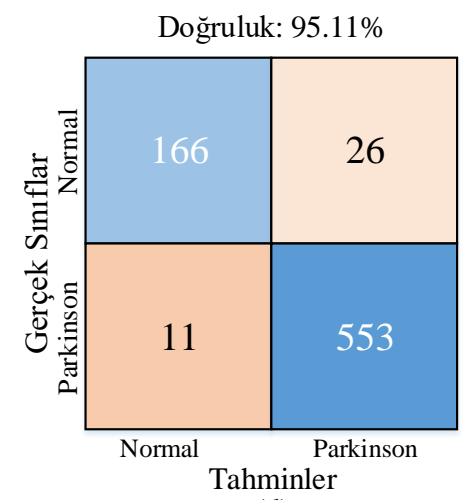

(d)

Şekil 3. Karmaşıklık matrisi: (a) DVM, (b) K-EYK, (c) RAUKT (d) ÇO

Tablo 2. Sintflandirıclların diğer performans metrikleri

\begin{tabular}{c|c|c|c|c|c}
\hline Sınıflandırıcı & Sınıflar & Duyarlılık & Özgüllük & Kesinlik & F-skor \\
\hline \multirow{2}{*}{ DVM } & Parkinson & 0.761 & 0.968 & 0.890 & 0.820 \\
\cline { 2 - 6 } & Normal & 0.968 & 0.760 & 0.922 & 0.945 \\
\hline \multirow{2}{*}{ K-EYK } & Parkinson & 0.838 & 0.961 & 0.880 & 0.859 \\
\cline { 2 - 6 } & Normal & 0.960 & 0.839 & 0.946 & 0.953 \\
\hline \multirow{2}{*}{ RAUKT } & Parkinson & 0.802 & 0.977 & 0.922 & 0.858 \\
\cline { 2 - 6 } & Normal & 0.977 & 0.802 & 0.935 & 0.956 \\
\hline \multirow{2}{*}{$\begin{array}{c}\text { CO ile } \\
\text { Siniflandırma }\end{array}$} & Parkinson & 0.865 & 0.980 & 0.938 & 0.900 \\
\cline { 2 - 6 } & Normal & 0.980 & 0.865 & 0.955 & 0.968 \\
\hline
\end{tabular}

Tablo 3. Aynı veri setini kullanan diğer yöntemler ile önerilen yöntemin karşılaştırılması

\begin{tabular}{l|c|c|c|c|c}
\hline Metotlar & Doğruluk (\%) & Duyarlılık & Özgüllük & Kesinlik & F-skor \\
\hline Sakar ve ark. (2019) & 86.00 & - & - & - & 0.840 \\
\hline Ashour ve ark. (2020) & 93.80 & 0.840 & 0.970 & 0.915 & - \\
\hline Önerilen Yöntem & 95.15 & 0.923 & 0.923 & 0.947 & 0.934 \\
\hline
\end{tabular}


Sakar ve ark. (2019) üzerinde PH vakalarının ses kayıtlarını kullanarak 753 adet konuşma tabanlı öznitelikler çıkarmıștır. Bu konuşma tabanlı öznitelikler MFCK, Temel Ses, Zaman-Frekans, DD, SK ve AQDK algoritmaları kullanarak oluşturulmuştur. Çıkartılan bu öznitelikler DVM, KEYK, Yapısal Bağıntı, Çok Katmanlı Algılayıcı, RD ve Saf Bayes algoritmaları ile sınıflandırılmıştır. En iyi performans, Dairesel Tabanlı Fonksiyonu çekirdek fonksiyonu olarak kullanan DVM sinıflandırıcısıyla elde edilmiştir ve \%86 doğruluk ile 0.84 F-skor değerlerine ulaşılmıştır. Ayrıca yapılan bu çalışmada çıkartılan özniteliklerin veri seti olarak kullanılması için açık erişim bağlantısı sağlanmıştır. $\mathrm{Bu}$ yüzden bu yöntem temel metot olarak kabul edilmiștir. Ashour ve ark. (2020), temel metodun performansını daha da geliştirmek için çıkartılan 753 özniteliği, öznitelik seçme algoritmaları ile azaltmıştır. Öznitelik seçme için Özyöney Merkeziyet (ÖM) ve Temel Bileşen Analizi (TBA) algoritmaları kullanılmıştır. ÖM algoritması, TBA algoritmasına göre $\% 2$ daha iyi sonuç vermiştir. Daha sonra ÖM algoritmasıyla seçilen 400 özniteliğe yine ÖM algoritmasıyla ikinci seviye bir öznitelik seçme işlemi uygulanmıştır. Seçilen 350 öznitelik 3. dereceden polinominal çekirdeğe sahip DVM algoritmasıyla eğitilmiştir. Doğruluk metriği temel metoda göre \% 7.80 oranında geliştirilmiştir. Önerilen yöntemde ise Ashour ve ark. (2020) metodundan doğruluk kriterinde \%1.35 oranında daha iyi bir skor elde edilmiştir. Diğer performans metriklerinde ise özgüllük hariç daha iyi skorlara ulaşılmıştır.

\section{SONUÇLAR}

$\mathrm{Bu}$ çalışmada, PH vakalarının ve sağlıklı bireylerin konuşma kayıtlarından PH'1 erken dönemde otomatik olarak teşhis etmek için etkin bir yaklaşım önerilmiştir. Bu yaklaşımda, ayırt ediciliği yüksek öznitelikleri çıkartmak için konuşma tabanlı öznitelik veri setine Ki-Kare ve L1-Norm DVM tabanlı öznitelik seçme algoritmaları uygulanmıştır. $\mathrm{Bu}$ algoritmalar ile ham öznitelik veri setini kullanan yöntemlere göre daha iyi bir başarım sağladığ 1 görülmüştür. $\mathrm{Bu}$ yöntemin başka bir katkısı ise Derin Ögrrenme (DÖ) modellerindeki zaman alıcı eğitim sürecinin bu modelde olmamasıdır. Fakat geleceğe yönelik çalışmalar için DÖ modelleri ile aynı veri setini kullanarak başarım karşılaştırılması yapılmasında fayda bulunmaktadır. Böylelikle, bilgisayar destekli uygulamalarda maliyet hesab1 yapıldıktan sonra en uygun model $\mathrm{PH}$ teşhis problemi için kullanılabilir.

Bu çalışmanın en büyük sınırlaması, kullanılan yöntemin daha büyük veri setlerine uygulaması durumunda daha güçlü bir donanım gerektirmesidir. Ayrıca bu çalışma ileride DÖ modelleriyle tekrar değerlendirilecektir ve mevcut çalışma ile karş1laştırılacaktır.

\section{ÇIKAR ÇATIŞMASI BEYANI}

Yazar bu makale ile ilgili herhangi bir çıkar çatışması bildirmemektedir.

\section{ARAŞTIRMA VE YAYIN ETÍĞİ BEYANI}

Yazar bu çalışmanın araştırma ve yayın etiğine uygun olduğunu beyan eder.

\section{KAYNAKLAR}

Adem, K. (2020). Diagnosis of breast cancer with Stacked autoencoder and Subspace kNN. Physica A: Statistical Mechanics and Its Applications, 551, 124591.

Ashour, A. S., El-Attar, A., Dey, N., Abd El-Naby, M. M., \& Abd El-Kader, H. (2018). Patient-dependent freezing of gait detection using signals from multiaccelerometer sensors in Parkinson's disease. 2018 9th Cairo International Biomedical Engineering Conference (CIBEC), 171-174.

Ashour, A. S., Nour, M. K. A., Polat, K., Guo, Y., Alsaggaf, W., \& El-Attar, A. (2020). A Novel Framework of Two Successive Feature Selection Levels Using Weight-Based Procedure for VoiceLoss Detection in Parkinson's Disease. IEEE Access, 8, 76193-76203.

Bloem, B. R., Grimbergen, Y. A. M., Cramer, M., Willemsen, M., \& Zwinderman, A. H. (2001). Prospective assessment of falls in Parkinson's disease. Journal of Neurology, 248(11), 950-958.

Bradley, P. S., \& Mangasarian, O. L. (1998). Feature selection via concave minimization and support vector machines. ICML, 98, 82-90.

Calabresi, P., Picconi, B., Parnetti, L., \& Di Filippo, M. (2006). A convergent model for cognitive dysfunctions in Parkinson's disease: the critical dopamine--acetylcholine synaptic balance. The Lancet Neurology, 5(11), 974-983.

Cortes, C., \& Vapnik, V. (1995). Support vector machine. Machine Learning, 20(3), 273-297.

Cover, T., \& Hart, P. (1967). Nearest neighbor pattern 
classification. IEEE Transactions on Information Theory, 13(1), 21-27.

Friedlander, A. H., Mahler, M., Norman, K. M., \& Ettinger, R. L. (2009). Parkinson disease: systemic and orofacial manifestations, medical and dental management. The Journal of the American Dental Association, 140(6), 658-669.

Goberman, A. M. (2005). Correlation between acoustic speech characteristics and non-speech motor performance in Parkinson disease. Medical Science Monitor, 11(3), CR109--CR116.

Guo, S., Guo, D., Chen, L., \& Jiang, Q. (2017). A L1regularized feature selection method for local dimension reduction on microarray data. Computational Biology and Chemistry, 67, 92-101.

Ho, T. K. (1998). Nearest neighbors in random subspaces. Lecture Notes in Computer Science (Including Subseries Lecture Notes in Artificial Intelligence and Lecture Notes in Bioinformatics), 1451, 640-648. https://doi.org/10.1007/bfb0033288

Jankovic, J. (2008). Parkinson's disease: clinical features and diagnosis. Journal of Neurology, Neurosurgery \& Psychiatry, 79(4), 368-376.

Kira, K., \& Rendell, L. A. (1992). A practical approach to feature selection. In Machine learning proceedings 1992 (pp. 249-256). Elsevier.

Orozco-Arroyave, J. R., Hönig, F., Arias-Londoño, J. D., Vargas-Bonilla, J. F., Daqrouq, K., Skodda, S., ... Nöth, E. (2016). Automatic detection of Parkinson's disease in running speech spoken in three different languages. The Journal of the Acoustical Society of America, 139(1), 481-500.

Ramig, L. O., Fox, C., \& Sapir, S. (2004). Parkinson's disease: speech and voice disorders and their treatment with the Lee Silverman Voice Treatment. Seminars in Speech and Language, 25(02), 169-180.

Sakar, C. O., Serbes, G., Gunduz, A., Tunc, H. C., Nizam, H., Sakar, B. E., ... Apaydin, H. (2019). A comparative analysis of speech signal processing algorithms for Parkinson's disease classification and the use of the tunable Q-factor wavelet transform. Applied Soft Computing, 74, 255-263.

Sengür, D., \& Turhan, M. (2018). Prediction of the action identification levels of teachers based on organizational commitment and job satisfaction by using k-nearest neighbors method. Turkish Journal of Science and Technology, 13(2), 61-68.

Trail, M., Fox, C., Ramig, L. O., Sapir, S., Howard, J., \& Lai, E. C. (2005). Speech treatment for Parkinson's disease. NeuroRehabilitation, 20(3), 205-221.

Tsanas, A., Little, M. A., McSharry, P. E., Spielman, J., \& Ramig, L. O. (2012). Novel speech signal processing algorithms for high-accuracy classification of Parkinson's disease. IEEE Transactions on Biomedical Engineering, 59(5), 1264-1271.

Turhan, M., Sengür, D., Karabatak, S., Guo, Y., \&
Smarandache, F. (2018). Neutrosophic weighted support vector machines for the determination of school administrators who attended an action learning course based on their conflict-handling styles. Symmetry, 10(5), 176. 